\title{
Erratum: "CTAB-PEG DNA Extraction from Fungi with High Contents of Polysaccharides"
}

\author{
X. Huang ${ }^{a}$, N. Duan ${ }^{a}$, H. Xu ${ }^{a}$, T. N. Xie ${ }^{a}$, Y.-R. Xue ${ }^{a}$, and C.-H. Liu ${ }^{a}$ * \\ ${ }^{a}$ State Key of Pharmaceutical Biotechnology, School of Life Science, Nanjing University, \\ Nanjing, 210023 China \\ *e-mail: chliu@nju.edu.cn
}

Submitted July 9, 2019; accepted for publication July 9, 2019

DOI: $10.1134 / \mathrm{S} 0026893319080016$

The original article can be found online at

DOI: $10.1134 /$ S0026893318040088

Page 622, in Reagents and Solutions should read $20 \mathrm{mg} / \mathrm{mL}$ proteinase K;

Page 622, in Reagents and Solutions should read $100 \mathrm{mg} / \mathrm{mL}$ RNase;

Page 622, in Paragraph 6 should read 0.25:0.11.

Page 623, Step 15 should read Transfer the upper aqueous phase to a fresh microfuge tube. Collect the DNA by precipitation with an equal volume of $20 \%$ PEG 8000 (pH 8.0, the contains $20 \%$ PEG 8000 w/v, $1.2 \mathrm{M} \mathrm{NaCl}$ ) for $1-2 \mathrm{~h}$ at $20^{\circ} \mathrm{C}$.

One page 623: RNaseA (100 mg/mL, TIANGEN RNase); 20\% PEG 8000 (pH 8.0, contains 20\% PEG $8000 \mathrm{w} / \mathrm{v}, \mathrm{NaCl} 1.2 \mathrm{M})$. 